\title{
UNSTABLE MANIFOLDS COMPUTATION FOR THE TWO-DIMENSIONAL PLANE POISEUILLE FLOW
}

\author{
PABLO S. CASAS \\ Departamento de Matemática Aplicada I. Universidad Politécnica de Cataluña, \\ Diagonal, 647; 08028 Barcelona. Spain, http://www-ma1.upc.es/ casas/ \\ ÀNGEL JORBA \\ Departamento de Matemática Aplicada y Análisis. Universidad de Barcelona, \\ Gran Via, 585; 08007 Barcelona. Spain, http://www.maia.ub.es/ angel/
}

In this work we study the connection among different configurations of the flow in the plane Poiseuille problem in dimension 2. The fluid is confined in a channel of plane parallel walls and modeled by the incompressible Navier-Stokes equations, together with $L$-periodic boundary conditions ( $L=2 \pi / \alpha$, being $\alpha$ the parameter wave number). We have considered the fluid driven by a constant flux or a mean pressure gradient, for which we have respective definitions of the Reynolds number, $R e_{Q}$ and $R e_{p}$. The numerical approximation is detailed in Casas ${ }^{1}$. In figure 1 we represent bifurcating curves of periodic and quasi-periodic flows obtained numerically in Casas ${ }^{1}$ using (as in the rest of the paper) $8 \times 70$ spectral modes in the spatial variables and $\Delta t=0.02$ as the time step. Each point of those curves represents the amplitude $A$. It is also marked on the curves the different stability regions, together with several Hopf bifurcations. In figure $1 \mathrm{~b}$ it is shown a family of quasi-periodic solutions. The computations have been carried out in a Beowulf cluster of PCs.

In the case of unstable periodic flows we consider the ones that have one real unstable eigenvalue and the remaining ones stable, or a couple of complex conjugate unstable eigenvalues and the remaining ones stable. For each of those periodic flows $u^{p}(x, y, t)$, we have studied its unstable manifold and which new state of the fluid they are connected to. By means of the Jacobian matrix of the linearized system, we can obtain the eigenvector $w$ associated with the unstable eigenvalue. We have followed the temporal evolution of the perturbed flow $u^{p}+r w$ until an attracting state is reached. The configurations obtained for several values of $R e_{p}, R e_{Q}$ and $\alpha$ are presented in table 1. Unstable periodic solutions for $R e_{p} \leqslant R e_{p 1}$ are connected to the laminar flow. The remaining solutions on the upper branch for both $R e_{p}$ and $R e_{Q}$ are attracted by a 2 -torus. For $R e_{p} \geqslant R e_{p 1}$ the attractor is the periodic solution on the upper branch for $\alpha=1.02056$, meanwhile for 
$\alpha=1.1$ this is so for $R e_{p} \leqslant R e_{p 2}$. For $R e_{p} \geqslant R e_{p 2}$ and $\alpha=1.1$ the solution is connected with 2 -torus and more complicated sets. We have an analogous situation for $\operatorname{Re}_{Q}$ and $\alpha=1.1$. We have followed a similar procedure for the case of unstable quasi-periodic flows, whose results are summarized in table 2. In figure 2 we present the evolution of perturbed flows as a projection of the discrete velocity on the plane of 2 selected coordinates when the flow crosses an appropriate Poincaré section.

Table 1. Attractors of the flow to which is connected the unstable manifold of periodic solutions on the upper and lower branch of the amplitude curve. The temporal evolution is presented in figures $2 \mathrm{a}$ and $2 \mathrm{~b}$ for $R e$ marked with '*' in the table.

\begin{tabular}{|c|c|c|c|c|c|c|c|c|c|}
\hline $\begin{array}{c}\alpha= \\
R e_{p}\end{array}$ & $\begin{array}{l}1.02056 \\
\text { attract. }\end{array}$ & \multicolumn{7}{|c|}{$\alpha=102056 \quad$ UPPER BRANCH } & $\begin{array}{l}=1.1 \\
\text { attract. }\end{array}$ \\
\hline $\begin{array}{l}4638 \\
4654 \\
4680 \\
6952 \\
7184 \\
7438 \\
7713 \\
8012 \\
8336\end{array}$ & $\begin{array}{l}\text { laminar } \\
\text { laminar } \\
\text { laminar } \\
\text { 2-torus } \\
\text { 2-torus } \\
\text { 2-torus } \\
\text { 2-torus } \\
\text { 2-torus } \\
\text { 2-torus }\end{array}$ & $\begin{array}{r}8688 \\
9067 \\
9478 \\
9921 \\
10398 \\
10912\end{array}$ & $\begin{array}{l}2 \text {-torus } \\
2 \text {-torus } \\
2 \text {-torus } \\
2 \text {-torus } \\
2 \text {-torus } \\
2 \text {-torus }\end{array}$ & $\begin{array}{l}3803 \\
3816 \\
3835 \\
7268 \\
7615 \\
7991 \\
8398 \\
8839 \\
9316\end{array}$ & $\begin{array}{l}\text { laminar } \\
\text { laminar } \\
\text { laminar } \\
\text { 2-torus } \\
\text { 2-torus } \\
\text { 2-torus } \\
\text { 2-torus } \\
\text { 2-torus } \\
\text { 2-torus }\end{array}$ & $\begin{array}{r}9832 \\
10388 \\
10990 \\
11638\end{array}$ & $\begin{array}{l}2 \text {-torus } \\
2 \text {-torus } \\
2 \text {-torus } \\
2 \text {-torus }\end{array}$ & $\begin{array}{l}5264 \\
5402 \\
5601 \\
5801 \\
6069 \\
6321 \\
6589 \\
6682 \\
6776\end{array}$ & $\begin{array}{l}2 \text {-torus } \\
2 \text {-torus } \\
2 \text {-torus } \\
2 \text {-torus } \\
2 \text {-torus } \\
2 \text {-torus } \\
2 \text {-torus } \\
2 \text {-torus } \\
2 \text {-torus }\end{array}$ \\
\hline $\begin{array}{c}\alpha= \\
R e_{p}\end{array}$ & $\begin{array}{l}1.02056 \\
\text { attract. }\end{array}$ & $\begin{array}{r}\alpha \\
R e_{p} \\
\end{array}$ & $\begin{array}{l}=1.1 \\
\text { attract. }\end{array}$ & $\begin{array}{c}\text { WER } \\
\alpha \\
R e_{p}\end{array}$ & $\begin{array}{l}\text { BRANCH } \\
=1.1 \\
\text { attract. }\end{array}$ & $\begin{array}{r}\alpha \\
\operatorname{Re}_{Q}\end{array}$ & $\begin{array}{l}=1.1 \\
\text { attract. }\end{array}$ & $\begin{array}{r}\alpha= \\
\operatorname{Re}_{Q}\end{array}$ & $\begin{array}{l}=1.1 \\
\text { attract. }\end{array}$ \\
\hline $\begin{array}{l}4636 \\
4649 \\
4689 \\
4722 \\
4766 \\
4821 \\
4890 \\
4975 \\
5079 \\
5205 \\
5361 \\
5554 \\
5772\end{array}$ & $\begin{array}{l}\text { laminar } \\
\text { laminar } \\
\text { laminar } \\
\text { laminar } \\
\text { periodic } \\
\text { periodic } \\
\text { periodic } \\
\text { periodic } \\
\text { periodic } \\
\text { periodic } \\
\text { periodic } \\
\text { periodic } \\
\text { periodic }\end{array}$ & $\begin{array}{l}3802 \\
3885 \\
3969 \\
4172 \\
4570 \\
4872 \\
5272 \\
5789 \\
6397 \\
6917 \\
7813 \\
8192 \\
8642 \\
9094\end{array}$ & $\begin{array}{l}\text { laminar } \\
\text { periodic } \\
\text { periodic } \\
\text { periodic } \\
\text { periodic } \\
\text { periodic } \\
\text { periodic } \\
\text { periodic } \\
\text { periodic } \\
\text { periodic } \\
\text { 2-torus } \\
\text { 2-torus } \\
2 \text {-torus } \\
2 \text {-torus }\end{array}$ & $\begin{array}{r}9489 \\
9589 \\
10513 \\
11078 \\
11375\end{array}$ & $\begin{array}{l}\text { 2-torus } \\
\text { unkn. } \\
\text { 2-torus } \\
\text { laminar } \\
\text { 2-torus }\end{array}$ & $\begin{array}{l}3658 \\
3694 \\
3816 \\
4020 \\
4559 \\
4611 \\
4814 \\
5101 \\
5500 \\
5822 \\
6049 \\
6499 \\
6791 \\
7097\end{array}$ & $\begin{array}{l}\text { periodic } \\
\text { periodic } \\
\text { periodic } \\
\text { periodic } \\
\text { periodic } \\
\text { periodic } \\
\text { periodic } \\
2 \text {-torus } \\
2 \text {-torus } \\
2 \text {-torus } \\
2 \text {-torus } \\
2 \text {-torus } \\
2 \text {-torus } \\
2 \text {-torus }\end{array}$ & $\begin{array}{c}7359 \\
7639 \\
7995 \\
8389^{*} \\
8682^{*} \\
9045 \\
9363 \\
9589 \\
9848 \\
10139 \\
10390 \\
10746 \\
11096 \\
11395\end{array}$ & $\begin{array}{l}\text { 2-torus } \\
\text { 2-torus } \\
\text { 3-torus } \\
\text { 3-torus } \\
\text { unkn. } \\
\text { unkn. } \\
\text { unkn. } \\
\text { unkn. } \\
\text { unkn. } \\
\text { unkn. } \\
\text { unkn. } \\
\text { unkn. } \\
\text { unkn. } \\
\text { unkn. }\end{array}$ \\
\hline
\end{tabular}

Table 2. Attractors of the flow to which is connected the unstable manifold of quasi-periodic solutions for $\operatorname{Re}_{Q}$ and $\alpha=1.1$. The temporal evolution of the flow until the attracting solution is reached is presented in figures $2 \mathrm{c}$ and $2 \mathrm{~d}$ for $R e$ marked with '*' in the table.

\begin{tabular}{|llllll|}
\hline$R e_{Q}$ & attractor & $R e_{Q}$ & attractor & $R e_{Q}$ & attractor \\
\hline 7953 & 3-torus & $8322^{*}$ & 3-torus & $9005^{*}$ & possible 3-torus \\
7975 & 3-torus & 8486 & 3-torus & 9096 & unknown \\
8043 & 3-torus & 8623 & 3-torus & 9204 & unknown \\
8157 & 3-torus & 8767 & 3-torus & & \\
8278 & 3-torus & 8894 & possible 3-torus & & \\
\hline
\end{tabular}

\section{References}

1. P. S. Casas. Numerical study of Hopf bifurcations in the two-dimensional plane Poiseuille flow. PhD thesis, Universidad Politécnica de Cataluña, September 2002. http://www-ma1.upc.es/〜 casas/research.html. 

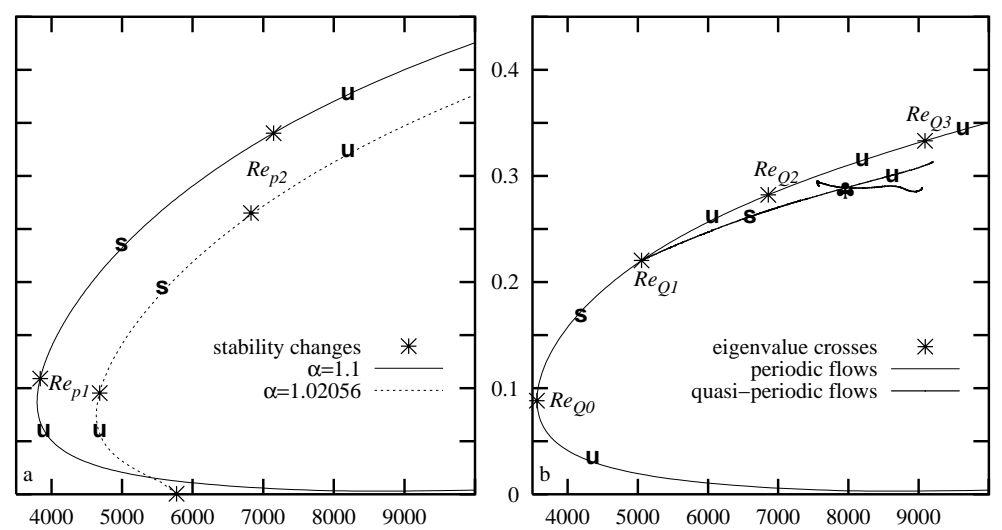

Figure 1. Bifurcating curves of amplitudes for periodic flows based on $\operatorname{Re}_{p}$ (a) and $\operatorname{Re}_{Q}$ (b). The '*' on each curve of (a) corresponds to Hopf bifurcations. They divide the different regions of stability to superharmonic disturbances, which are also labeled in the plot as 's' for "stable" and 'u' for "unstable". The plot in (b) is the analogous of (a) but including a branch of quasi-periodic flows. At $R e_{Q 0}$ there is no bifurcation whereas three Hopf bifurcations labeled as $R e_{Q 1}, R e_{Q 2}$, and $R e_{Q 3}$ are presented on the upper branch. The symbol indicates a Hopf bifurcation in the curve of quasi-periodic flows.
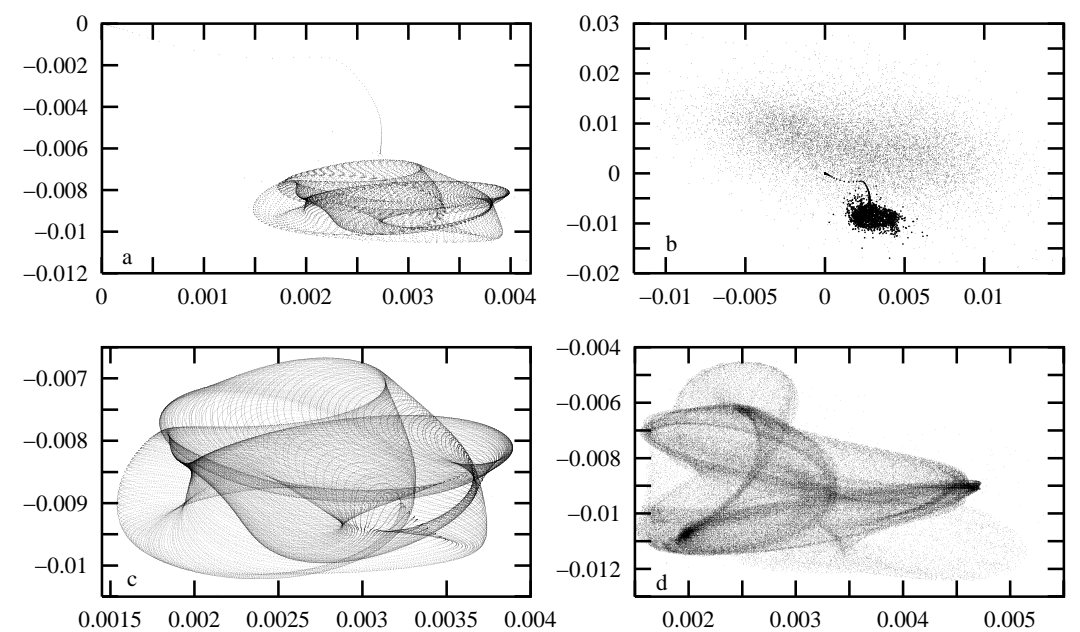

Figure 2. Different time-evolutions of perturbed flows. In (a) and (b) the flow starts from the perturbed unstable periodic solution on the lower branch for $R e_{Q}=8389$ and $\operatorname{Re}_{Q}=8682$ respectively, and $\alpha=1.1$. In (a) the fluid is first directed to the unstable periodic solution on the upper branch and then attracted by a 3 -torus. In (b) the fluid is attracted by a strange set plotted in bigger dots, which is unstable and finally drives the fluid to another strange set. In (c) the perturbed 2-torus for $\operatorname{Re}_{Q}=8322$ is attracted by a nearly resonant 3-torus, as can be observed. Finally in (d) the perturbed 2-torus for $\operatorname{Re}_{Q}=9005$ is attracted by a set that reminds a 3 -torus. 